\title{
Leksikostatistik Bahasa \\ (Sasambo) Bahasa Sasak, Bahasa Sumbawa/Samawa, Dan Bahasa \\ Bima/Mbojo : \\ Kajian Linguistik Historis Komparatif
}

\author{
Moh. Hilmi \\ STIT Palapa Nusantara \\ hilmimoh7@gmail.com
}

\begin{abstract}
Abstrak: Penelitian ini mengkaji Bahasa (Sasambo) Sasak, Bahasa Sumbawa, Dan Bahasa Bima yang termasuk ke dalam rumpun Austronesia atau Melayu Polinesia. Asumsi mengenai kekerabatan ketiga bahasa yakni pada kenyataan adanya kesamaan dan kemiripan dalam bentuk dan makna yang merupakan pantulan dari warisan sejarah yang sama. Hasil penelitian menunjukan bahwa Bahasa (Sasambo) Sasak, Bahasa Sumbawa, Dan Bahasa Bima termasuk dalam kategori keluarga (family) bahasa. Persentase kata kerabat bahasa sasak dan bahasa sumbawa sebesar 53\%, bahasa sasak dan bahasa bima sebesar 57\%, bahasa Sumbawa dan bahasa bima sebesar $62 \%$. Bahasa Sasak dan bahasa Sumbawa merupakan bahasa tunggal pada 1590-1336 tahun yang lalu, diperkirakan mulai berpisah dari bahasa Proto kira-kira tahun 422-676 M. Bahasa Sasak dan bahasa Bima merupakan bahasa tunggal pada 1411-1177 tahun yang lalu, diperkirakan mulai berpisah dari bahasa Proto kira-kira tahun 601-835 M. Bahasa Sumbawa dan bahasa Bima merupakan bahasa tunggal pada 1207-995 tahun yang lalu, diperkirakan mulai berpisah dari bahasa Proto kira-kira tahun 8051017 M (dihitung pada tahun 2012).
\end{abstract}

Kata kunci: Bahasa Sasambo, leksikostatistik, kekerabatan, dan waktu pisah. 


\section{Pendahuluan}

Bangsa Indonesia adalah salah satu bangsa yang majemuk, terdiri atas berbagai macam suku yang tersebar di tanah air. Setiap suku memiliki Bahasa tersendiri untuk berkomunikasi, baik sesama etnis maupun antaretnis. Bahasa memiliki peranan penting sebagai sarana komunikasi untuk menyampaikan maksud dan pokok pikiran manusia serta mengekspresikan dirinya dalam interaksi di masyarakat.

Seiring dengan perjalanan waktu, bahasa akan mengalami perubahan dan perkembangan. Perubahan dan perkembangan bahasa berbanding lurus dengan penuturnya serta dipengaruhi oleh gerak migrasi penyebaran bahasa-bahasa induk.

Bahasa-bahasa yang berasal dari satu induk asal (cognate) memiliki hubungan kekerabatan pada zaman lampau. Hal ini ditunjukkan dengan adanya persamaan bentuk dan makna yang merupakan pantulan dari sejarah warisan yang sama (Keraf, 1996:34). ${ }^{1}$

Pengelompokan bahasa-bahasa Austronesia yang mengacu pada kerangk dasar Salzner, S.J. Esser, dan dilengkapi dengan catatan-catatan milik Dyen, menyebutkan bahwa bahasa Sasak, bahasa Sumbawa, dan bahasa Bima merupakan kelompok bahasa Austronesia Barat (Keraf, 1996:206; Sudarno, 1994:112). ${ }^{2}$

Bagan 1: Pengelompokan bahasa di Indonesia menurut S.J. Esser $1938^{3}$. :

1. Kelompokan Sumatra

2. Kelompok Jawa

3. Kelompok dayak Kalimantan

4. Kelompok Bali-sasak

5. Kelompok Sulawesi Utara

6. Kelompok Gorontalo

7. Kelompok Tomini

8. Kelompok Toraja

9. Kelompok Loinang-Banggai

10. Kelompok Bungku-Laki

11. Kelompok Sulawesi Selatan

12. Kelompok Muna-Butung

13. Kelompok Bima-sumba

14. Kelompok Ambon-Timor

15. Kelompok sula-Bacan

16. Kelompok Halmahera Selatan dan Iran

17. Kelompok Melanesia.

Bahasa Sasak, bahasa Sumbawa, dan bahasa Bima secara letak geografis sangat berdekatan yakni berada di pulau Lombok dan Sumbawa, lebih tepatnya di Provinsi NTB, serta berasal dari satu rumpun bahasa atau kelompok Sasak dan Samawa dan Mbojo yang ternyata memperlihatkan adanya hubungan kekerabatan.

Dari pengelompokan di atas, dapat diketahui sistem kekerabatan, usia bahasa, dan waktu pisah berdasarkan sifat kekerabatannya, yakni berdasarkan unsur fonemis serta leksikonnya. Berdasarkan hal itu dapat diketahui bahasa mana yang memiliki kekerabatan lebih dekat dan bahasa mana yang mempunyai waktu pisah yang lebih tua.

\footnotetext{
${ }^{1}$ Keraf, Gorys. 1996. Linguistik Bandingan Historis. Jakarta: Gramedia Pustaka Utama.

2 Sudarno, M. Ed. 1994. Perbandingan Bahasa Nusantara. Jakarta: Arikha Medika Cipta.

${ }^{3}$ http:/ / www.linguistikid.com/2016/11/ kajian-dan-jenis-tipologi-bahasa.html
} 


\section{Pembahasan}

Penelitian ini dikaji dengan menggunakan metode pengelompokan bahasa serta teknik leksikostatistik. Tahap pertama, mengumpulkan 300 kosakata dasar yang disusun oleh Morris Swades. Metode yang digunakan dalam penyediaan data ini adalah metode referensial, sedangkan teknik yang digunakan adalah teknik catat (Kesuma, 2007:48; Sudaryanto, 1993:13-16; Sudaryanto, 1988:5) ${ }^{4}$. Kedua, menetapkan kata kerabat (cognate) guna mencari persentase kekerabatan dari ketiga bahasa dengan cara mengklasifikasikan berdasarkan: (a) pasangan yang identik, (b) pasangan yang berkorespondensi fonemis, (c) pasangan yang mirip secara fonetis, (d) pasangan yang berbeda satu fonem. Ketiga, menghitung usia dan waktu pisah ketiga bahasa serta menghitung pula jangka kesalahan untuk menetapkan waktu pisah yang lebih tepat. Keempat, penyusunan klasifikasi sistem kekerabatan, apakah sebagai satu bahasa (language), keluarga bahasa (subfamily), rumpun bahasa (stock), mikrofilum, mesofilum, atau makrofilum (Keraf, 1996:126-128).

\section{Leksikostatistik pada Bahasa Sasak dan Bahasa Sumbawa}

Seusai menetapkan kata kerabat, langkah selanjutnya yakni mencari persentase kerabat dengan rumus:

$$
\mathrm{C}=\mathrm{Vt} \times 100 \%
$$

\section{$\mathrm{Vd}$}

Keterangan:

$\mathrm{C}=$ kata kerabat; $\mathrm{Vt}=$ jumlah kosakata kerabat; $\mathrm{Vd}=$ jumlah gloss yang diperhitungkan

$$
\mathrm{C}=\mathrm{Vt} \times 100 \% \quad=157 \times 100 \%=0,53 \times 100 \%=53 \%
$$

$\overline{\mathrm{Vd}}$

Setelah persentase kerabat diketahui hasilnya, kita dapat menghitung waktu pisah dari bahasa Sasak dan bahasa Sumbawa

$$
\begin{aligned}
& \text { diketahui: } \quad \mathrm{C}=53 \% \\
& \log r=80,5 \% \\
& \text { ditanya: } \quad \mathrm{W}_{1=} \ldots \ldots \text { ? } \\
& \text { jawab: } \quad \mathrm{W}_{1}=\log . \mathrm{C} \quad \mathrm{W}_{1}=\overline{\log 0,53} \\
& 2 \text { log.r } \quad 2 \times \log 0,805 \\
& \mathrm{~W}_{1}=\quad-0,635 \quad \mathrm{~W}_{1}=-0,635 \quad \mathrm{~W}_{1}=1,463 \\
& 2 \overline{\mathrm{x}(-0,217)} \quad-0,434
\end{aligned}
$$

Waktu pisah tersebut dikali 1000 sehingga hasilnya menjadi 1.463

\footnotetext{
${ }^{4}$ Kesuma, Tri Mastoyo Jati. 2007. Pengantar (Metode) Penelitian Bahasa. Yogyakarta:

Carasvatibooks.

${ }^{5}$ Keraf, Gorys. 1996. Linguistik Bandingan Historis. Jakarta: Gramedia Pustaka Utama
} 
Jadi, perhitungan waktu pisah awal bahasa Sasak dan bahasa Sumbawa adalah 1.463 yang lalu. Dengan kata lain, perhitungan waktu pisah awal bahasa Sasak dan bahasa Sumbawa dapat dinyatakan sebagai berikut:

(1) Bahasa Sasak dan bahasa Sumbawa diperkirakan merupakan satu bahasa tunggal sekitar 1.463 tahun yang lalu.

(2) Bahasa Sasak dan bahasa Sumbawa diperkirakan mulai berpisah dari bahasa induknya kira-kira pada abad 549 Masehi (dihitung pada tahun 2012).

Setelah waktu pisah dari bahasa Sasak dan bahasa Sumbawa diketahui hasilnya, langkah selanjutnya yakni menghitung jangka kesalahan. Hal ini dilakukan untuk menghindari kesalahan penghitungan serta menetapkan waktu pisah yang lebih tepat. Perlu diingat bahwa untuk mengantisipasi kesalahan dalam statistik adalah memberi suatu perkiraan, yakni bukan dalam waktu tertentu, melainkan dalam suatu jangka waktu tertentu. Untuk menghitung jangka kesalahan dapat menggunakan rumus:

$$
\mathrm{S}=\frac{\sqrt{\mathrm{C}(1-\mathrm{C})}}{\mathrm{n}}
$$

Keterangan:

$\mathrm{S}=$ Kesalahan standar dalam persentase kata kerabat

$\mathrm{C}=$ Persentase kata kerabat

$\mathrm{n}=$ Jumlah kata yang diperbandingkan, baik kerabat maupun non-kerabat diketahui: $\mathrm{C}=0,53$

$$
\begin{aligned}
& \begin{aligned}
\mathrm{n} & =296 \\
\text { ditanya:S } & =\ldots . . ?
\end{aligned} \\
& \text { jawab: } \\
& S=\sqrt{C(1-C)} \\
& S=\sqrt{0,53(1-0,53)} \\
& S=\frac{\sqrt{0,53 \times 0,4} 47}{296} \quad S=\frac{\sqrt{0,2491}}{296} \\
& \mathrm{~S}=\sqrt{8,415} \quad \mathrm{~S}=0,029 \text { (dibulatkan menjadi } 0,03 \text { ) }
\end{aligned}
$$

Hasil dari kesalahan standar ini $(0,03)$ dijumlahkan dengan persentase kerabat

awal $\left(\mathrm{C}_{1}\right)$ untuk mendapatkan $\mathrm{C}_{2}\left(\mathrm{C}_{2}=\mathrm{C}_{1}+\mathrm{S}\right)$. Jadi $\mathrm{C}_{2}$ hasilnya adalah $0,53+0,03=0,56$. Dengan adanya $\mathrm{C}_{2}$, maka waktu pisah dapat dihitung kembali, dengan menggunakan rumus yang sama:

$$
\begin{aligned}
& \begin{array}{llll}
\text { diketahui: } \quad \mathrm{C}_{2}=56 \% & \log \mathrm{r}=0,805
\end{array} \\
& \text { ditanya: } \quad \mathrm{W}_{2=}=\ldots \ldots \text { ? } \\
& \text { jawab: } \quad \mathrm{W}_{2}=\log 0,56 \quad \mathrm{~W} 2=\log 0,56 \\
& \overline{2 \log 0,805} \quad \overline{2 \times \log 0,805} \\
& \mathrm{~W}_{2}=-0,580 \quad \mathrm{~W} 2=-0,580 \\
& \overline{2 \times-0,217}-0,434 \\
& \mathrm{~W}_{2}=1,336
\end{aligned}
$$


Waktu pisah tersebut dikali 1000 sehingga hasilnya menjadi 1.336

Dengan demikian, jangka kesalahan $=\mathrm{W}_{1}-\mathrm{W}_{2}=1.463-1.336=127$

Jadi, usia bahasa Sasak dan bahasa Sumbawa dapat dinyatakan sebagai berikut:

(1) Bahasa Sasak dan bahasa Sumbawa diperkirakan merupakan satu bahasa tunggal sekitar $1.463 \pm 127$ tahun yang lalu.

(2) Bahasa Sasak dan bahasa Sumbawa merupakan bahasa tunggal pada 1590-1336 tahun yang lalu.

(3) Bahasa Sasak dan bahasa Sumbawa diperkirakan mulai berpisah dari bahasa induknya kira-kira pada 422-676 Masehi (dihitung pada tahun 2012).

\section{Leksikostatistik pada Bahasa Sasak dan Bahasa Bima}

Seusai menetapkan kata kerabat, langkah selanjutnya yakni mencari persentase kerabat dengan rumus:

$$
\mathrm{C}=\mathrm{Vt} \times 100 \%
$$

\section{$\mathrm{Vd}$}

Keterangan:

$\mathrm{C}=$ kata kerabat; $\mathrm{Vt}=$ jumlah kosakata kerabat; $\mathrm{Vd}=$ jumlah gloss yang diperhitungkan

$$
\begin{aligned}
& \mathrm{C}=\mathrm{Vt} \times 100 \% \quad=170 \times 100 \% \quad=0,57 \times 100 \% \quad=57 \% \\
& \overline{\mathrm{Vd}} \overline{297}
\end{aligned}
$$

Setelah persentase kerabat diketahui hasilnya, kita dapat menghitung waktu pisah dari bahasa Sasak dan bahasa Bima

$$
\begin{aligned}
& \text { diketahui: } \mathrm{C}=57 \% \quad \log \mathrm{r}=80,5 \% \\
& \text { ditanya: } \mathrm{W}_{1=} \ldots \ldots \text { ? } \\
& \text { jawab: } \quad \mathrm{W} 1=\log . \mathrm{C} \quad \mathrm{W}_{1}=\log 0,57 \\
& \mathrm{~W} 1=\begin{array}{l}
\overline{2 \log . \mathrm{r}} \\
\frac{-0,562}{2 \times(-0,217)}
\end{array} \quad \mathrm{W}_{1}=\frac{\overline{2 \times \log 0,805}}{-0,562} \quad \mathrm{~W}_{1}=1,294
\end{aligned}
$$

Waktu pisah tersebut dikali 1000 sehingga hasilnya menjadi 1.294

Jadi, perhitungan waktu pisah awal bahasa Sasak dan bahasa Bima adalah 1.294 yang lalu. Dengan kata lain, perhitungan waktu pisah awal bahasa Sasak dan bahasa Bima dapat dinyatakan sebagai berikut:

(1) Bahasa Sasak dan bahasa Bima diperkirakan merupakan satu bahasa tunggal sekitar 1.294 tahun yang lalu. 
(2) Bahasa Sasak dan bahasa Bima diperkirakan mulai berpisah dari bahasa induknya kira-kira pada abad 718 Masehi (dihitung pada tahun 2012).

Setelah waktu pisah dari bahasa Sasak dan bahasa Sumbawa diketahui hasilnya, langkah selanjutnya yakni menghitung jangka kesalahan. Hal ini dilakukan untuk menghindari kesalahan penghitungan serta menetapkan waktu pisah yang lebih tepat. Perlu diingat bahwa untuk mengantisipasi kesalahan dalam statistik adalah memberi suatu perkiraan, yakni bukan dalam waktu tertentu, melainkan dalam suatu jangka waktu tertentu. Untuk menghitung jangka kesalahan dapat menggunakan rumus:

$$
S=\frac{\sqrt{C(1-C)}}{n}
$$

\section{Keterangan:}

$\mathrm{S}=$ Kesalahan standar dalam persentase kata kerabat

$\mathrm{C}=$ Persentase kata kerabat

$\mathrm{n}=$ Jumlah kata yang diperbandingkan, baik kerabat maupun non-kerabat diketahui: $\mathrm{C}=0,57$

$$
\mathrm{n} \quad=297
$$

ditanya:S $=\ldots . . ?$

jawab:

$$
\begin{array}{ll}
\mathrm{S}=\frac{\sqrt{ } \mathrm{C}(1-\mathrm{C})}{\mathrm{n}} & \mathrm{S}=\frac{\sqrt{0,57(1-0,57)}}{297} \\
\mathrm{~S}=\frac{\sqrt{0,57 \times 0,43}}{297} & \mathrm{~S}=\frac{\sqrt{0,2451}}{297} \\
\mathrm{~S}=\sqrt{8,252} & \mathrm{~S}=0,028 \text { (dibulatkan menjadi } 0,03)
\end{array}
$$

Hasil dari kesalahan standar ini $(0,03)$ dijumlahkan dengan persentase kerabat awal $\left(C_{1}\right)$ untuk mendapatkan $C_{2}\left(C_{2}=C_{1}+S\right)$. Jadi $C_{2}$ hasilnya adalah $0,57+0,03=0,60$. Dengan adanya $\mathrm{C}_{2}$, maka waktu pisah dapat dihitung kembali, dengan menggunakan rumus yang sama:

$$
\begin{aligned}
& \text { diketahui: } \quad \mathrm{C}_{2} \quad=60 \% \quad \log \mathrm{r}=0,805 \\
& \text { ditanya: } \quad \mathrm{W}_{2=} \ldots \ldots \text { ? } \\
& \text { jawab: } \quad \mathrm{W}_{2}=\log 0,60 \quad \mathrm{~W}_{2}=\log 0,60 \\
& \overline{2 \log 0,805} \overline{2 \times \log 0,805} \\
& \mathrm{~W}_{2}=-0,511 \quad \mathrm{~W}_{2}=-0,511 \\
& \overline{2 \times-0,217} \quad \overline{-0,434} \\
& \mathrm{~W}_{2}=1,177
\end{aligned}
$$


Waktu pisah tersebut dikali 1000 sehingga hasilnya menjadi 1.177

Dengan demikian, jangka kesalahan $=\mathrm{W}_{1}-\mathrm{W}_{2}=1.294-1.177=117$

Jadi, usia bahasa Sasak dan bahasa Bima dapat dinyatakan sebagai berikut:

(1) Bahasa Sasak dan bahasa Bima diperkirakan merupakan satu bahasa tunggal sekitar $1.294 \pm 117$ tahun yang lalu.

(2) Bahasa Sasak dan bahasa Bima merupakan bahasa tunggal pada 1411-1177 tahun yang lalu.

(3) Bahasa Sasak dan bahasa Bima diperkirakan mulai berpisah dari bahasa induknya kira-kira pada 601-835 Masehi (dihitung pada tahun 2012).

\section{Leksikostatistik pada Bahasa Sumbawa dan Bahasa Bima}

Seusai menetapkan kata kerabat, langkah selanjutnya yakni mencari persentase kerabat dengan rumus:

$\mathrm{C}=\mathrm{Vt} \times 100 \%$

\section{$\mathrm{Vd}$}

Keterangan:

$\mathrm{C}=$ kata kerabat; $\mathrm{Vt}=$ jumlah kosakata kerabat; $\mathrm{Vd}=$ jumlah gloss yang

diperhitungkan

$\mathrm{C}=\mathrm{Vt} \times 100 \% \quad=183 \times 100 \% \quad=0, \times 100 \%=62 \%$

$\overline{\mathrm{Vd}} \quad \overline{296}$

Setelah persentase kerabat diketahui hasilnya, kita dapat menghitung waktu pisah dari bahasa Sumbawa dan bahasa Bima

$$
\begin{aligned}
& \text { diketahui: } \mathrm{C}=62 \% \quad \log \mathrm{r}=80,5 \% \\
& \text { ditanya: } \quad \mathbb{W}_{1=} \ldots \ldots \text { ? } \\
& \text { jawab: } \quad \mathrm{W}_{1}=\log \cdot \mathrm{C} \quad \mathrm{W}_{1}=\log 0,62 \\
& 2 \log . \mathrm{r} \quad 2 \times \log 0,805 \\
& \mathrm{~W}_{1}=-0,478 \quad \mathrm{~W}_{1}=-0,478 \quad \mathrm{~W}_{1}=1,101 \\
& 2 \overline{\mathrm{x}(-0,217)} \quad-0,434
\end{aligned}
$$

Waktu pisah tersebut dikali 1000 sehingga hasilnya menjadi 1.101 
Jadi, perhitungan waktu pisah awal bahasa Sumbawa dan bahasa Bima adalah 1.101

yang lalu. Dengan kata lain, perhitungan waktu pisah awal bahasa Sumbawa dan bahasa Bima dapat dinyatakan sebagai berikut:

(1) Bahasa Sumbawa dan bahasa Bima diperkirakan merupalan satu bahasa tunggal sekitar 1.101 tahun yang lalu.

(2) Bahasa Sumbawa dan bahasa Bima diperkirakan mulai berpisah dari bahasa induknya kira-kira pada abad 911 Masehi (dihitung pada tahun 2012).

Setelah waktu pisah dari bahasa Sasak dan bahasa Sumbawa diketahui hasilnya, langkah selanjutnya yakni menghitung jangka kesalahan. Hal ini dilakukan untuk menghindari kesalahan penghitungan serta menetapkan waktu pisah yang lebih tepat. Perlu diingat bahwa untuk mengantisipasi kesalahan dalam statistik adalah memberi suatu perkiraan, yakni bukan dalam waktu tertentu, melainkan dalam suatu jangka waktu tertentu. Untuk menghitung jangka kesalahan dapat menggunakan rumus:

$$
\mathrm{S}=\frac{\sqrt{\mathrm{C}(1 \mathrm{C})}}{\mathrm{n}}
$$

Keterangan:

$\mathrm{S}=$ Kesalahan standar dalam persentase kata kerabat

$\mathrm{C}=$ Persentase kata kerabat

$\mathrm{n}=$ Jumlah kata yang diperbandingkan, baik kerabat maupun non-kerabat diketahui: $\mathrm{C}=0,62$

$$
\mathrm{n}=296
$$

ditanya:S $=\ldots . . ?$

jawab:

$$
\begin{array}{lc}
\mathrm{S}=\sqrt{\mathrm{V} C(1-\mathrm{C})} & \mathrm{S}=\sqrt{0,62(1-0,62)} \\
\mathrm{S}=\frac{\sqrt{0,62 \times 0,38}}{296} & \mathrm{~S}=\sqrt{\frac{296}{0,2356}} \\
\mathrm{~S}=\sqrt{7,959} & \mathrm{~S}=0,028 \text { (dibulatkan menjadi } 0,03)
\end{array}
$$

Hasil dari kesalahan standar ini $(0,03)$ dijumlahkan dengan persentase kerabat awal $\left(C_{1}\right)$ untuk mendapatkan $C_{2}\left(C_{2}=C_{1}+S\right)$. Jadi $C_{2}$ hasilnya adalah $0,62+0,03=0,65$. Dengan adanya $\mathrm{C}_{2}$, maka waktu pisah dapat dihitung kembali, dengan menggunakan rumus yang sama:

$$
\text { diketahui: } \quad \mathrm{C} 2 \quad=65 \%
$$




$$
\begin{aligned}
& \log r=0,805 \\
& \text { ditanya: } \mathrm{W} 2=\ldots \ldots . ? \\
& \text { jawab: } \quad \mathrm{W}_{2}=\log 0,65 \\
& \mathrm{~W}=\log 0,65 \\
& 2 \log 0,805 \\
& 2 \times \log 0,805 \\
& \mathrm{~W}=-0,432 \\
& \mathrm{~W}=-0,432 \\
& \overline{2 \mathrm{x}-0,217} \\
& -0,434 \\
& \mathrm{~W}=0,995
\end{aligned}
$$

Waktu pisah tersebut dikali 1000 sehingga hasilnya menjadi 995

Dengan demikian, jangka kesalahan $=\mathrm{W}_{1}-\mathrm{W}_{2}=1.101-995=106$

Jadi, usia bahasa Sumbawa dan bahasa Bima dapat dinyatakan sebagai berikut:

(1) Bahasa Sumbawa dan bahasa Bima diperkirakan merupakan satu bahasa tunggal sekitar $1.101 \pm 106$ tahun yang lalu.

(2) Bahasa Sumbawa dan bahasa Bima merupakan bahasa tunggal pada 1207995 tahun yang lalu.

(3) Bahasa Sasak dan bahasa Sumbawa diperkirakan mulai berpisah dari bahasa induknya kira-kira pada 805-1017 Masehi (dihitung pada tahun 2012).

Teknik leksikostatistik tidak hanya berfungsi untuk menentukan persentase

kata kerabat serta menghitung usia bahasa, tetapi juga dapat digunakan untuk pengelompokan bahasa-bahasa kerabat. Bahasa-bahasa yang memperlihatkan persentase kekerabatan yang tinggi merupakan kelompok yang lebih dekat keanggotaannya, sedangkan yang persentase kekerabatannya rendah merupakan kelompok yang tingkat keanggotaanya atau kekerabatannya lebih jauh.

Swadesh mengusulkan klasifikasi sistem kekerabatan bahasa, yaitu:

\begin{tabular}{|l|c|c|}
\hline Tingkatan bahasa & Waktu pisah dalam abad & Persentase kata kerabat \\
\hline Bahasa (Language) & $0-5$ & $100-81$ \\
\hline Keluarga (Language Family) & $5-25$ & $81-36$ \\
\hline Rumpun (Stock) & $25-50$ & $36-12$ \\
\hline Mikrofilum & $50-75$ & $12-4$ \\
\hline Mesofilum & $75-100$ & $4-1$ \\
\hline Makrofilum & $100-$ ke atas & 1 - kurang dari 1 \%
\end{tabular}


(Sumber: Keraf, 1996:135)

Klasifikasi ini digunakan untuk mengetahui bagaimana kedudukan atau hubungan antara bahasa kerabat yang satu dengan bahasa kerabat yang lainnya. Sebelum dilakukan pengelompokan bahasa, alangkah baiknya jika kita melihat terlebih dahulu tingkat persentase kekerabatan dari masing-masing bahasa.

1. Grafik Persentase Kekerabatan Bahasa Sasak, Bahasa Sumbawa, dan Bahasa Bima

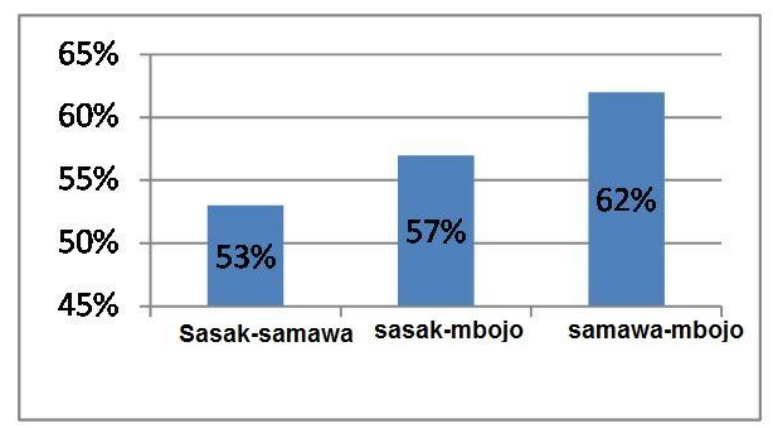

Grafik di atas menunjukan bahwa persentase kata kerabat dari bahasa Sasak, bahasa Sumbawa, dan bahasa Bima cukup bervariasi. Persentase kata kerabat yang terbesar adalah antara bahasa Sumbawa dan bahasa Bima sebesar 62\%, bahasa Sasak dan bahasa Sumbawa sebesar 53\%, serta bahasa Sasak dan bahasa Bima sebesar 57\%. Berdasarkan perbandingan persentase, kita dapat menarik kesimpulan bahwa antara bahasa Sumbawa dan bahasa Bima memiliki tingkat kekerabatan yang lebih dekat dibandingkan dengan bahasa Sasak-Sumbawa maupun bahasa Sasak-Bima.

Setelah mengetahui persentase kata kerabat dari masing-masing bahasa, langkah selanjutnya yaitu menyusun grafik pencabangan atau silsilah kekerabatan (stammbaum) dari bahasa Sasak, bahasa Sumbawa, dan bahasa Bima.

\section{Grafik Silsilah Kekerabatan Bahasa Sasak, Bahasa Sumbawa, dan Bahasa Bima}

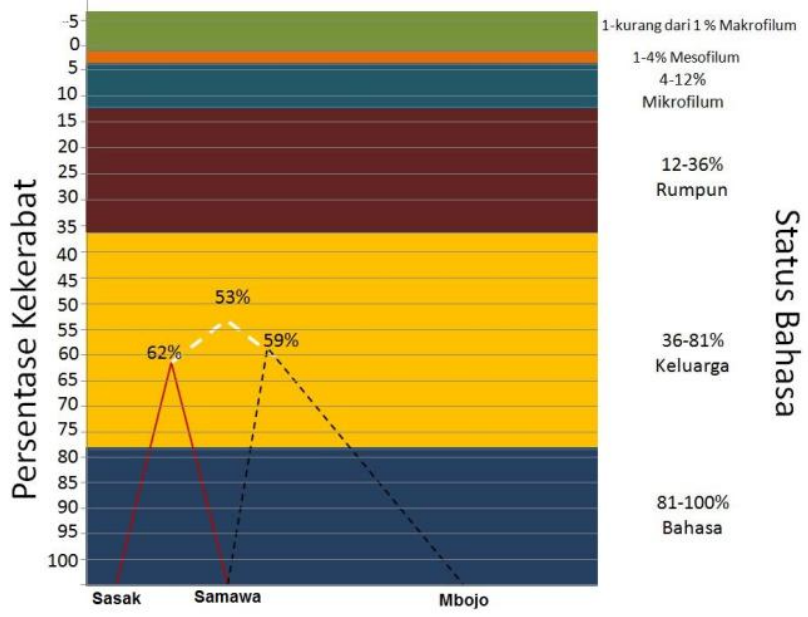

Lewat penjabaran grafik di atas, dapat diketahui bahwa (i) silsilah kekerabatan dari bahasa Sumbawa dan bahasa Bima lebih dekat dibanding dengan bahasa Sasak- 
Sumbawa maupun bahasa Sasak-Bima, (ii) secara leksikostatistik status bahasa dari bahasa Sasak, bahasa Sumbawa dan bahasa Bima adalah kategori keluarga (family).

\section{Penutup}

Berdasarkan uraian di atas, penulis menyimpulkan sebagai berikut:

1. Dari 300 kosakata untuk bahasa Sasak dan bahasa Sumbawa, hanya 296 pasangan yang lengkap, 4 glos yang tidak diperhitungkan. Dari 296 pasangan yang lengkap, terdapat 157 pasangan kata kerabat atau hanya 53\% kata kerabat. Bahasa Sasak dan bahasa Sumbawa diperkirakan merupakan satu bahasa tunggal sekitar 1.463 \pm 127 tahun yang lalu atau pada 1590-1336 tahun yang lalu. Bahasa Sasak dan bahasa Sumbawa diperkirakan mulai berpisah dari bahasa induknya kira-kira pada 422-676 Masehi (dihitung pada tahun 2012).

2. Dari 300 kosakata untuk bahasa Sasak dan bahasa Bima, hanya 297 pasangan yang lengkap, 3 glos yang tidak diperhitungkan. Dari 297 pasangan yang lengkap, terdapat 170 pasangan kata kerabat atau hanya 57\% kata kerabat. Bahasa Sasak dan bahasa Bima diperkirakan merupakan satu bahasa tunggal sekitar $1.294 \pm 117$ tahun yang lalu atau pada 1411-1177 tahun yang lalu. Bahasa Sasak dan bahasa Bima diperkirakan mulai berpisah dari bahasa induknya kira-kira pada 601-835 Masehi (dihitung pada tahun 2012).

3. Dari 300 kosakata untuk bahasa Sumbawa dan bahasa Bima, hanya 296 pasangan yang lengkap, 4 glos yang tidak diperhitungkan. Dari 296 pasangan yang lengkap, terdapat 183 pasangan kata kerabat atau hanya 62\% kata kerabat. Bahasa Sumbawa dan bahasa Bima diperkirakan merupakan satu bahasa tunggal sekitar $1.101 \pm 106$ tahun yang lalu atau pada 1207-995 tahun yang lalu. Bahasa Sasak dan bahasa Bima diperkirakan mulai berpisah dari bahasa induknya kira-kira pada 8051017 Masehi (dihitung pada tahun 2012).

4. Dari persentase kata kerabat yang menunjukan bahwa bahasa Sasak dan bahasa Sumbawa sebesar 53\%, bahasa Sasak dan bahasa Bima sebesar 57\%, serta bahasa Sumbawa dan bahasa Bima sebesar 62\%, dapat ditarik simpulan bahwa bahasa Sumbawa dan bahasa Bima mempunyai tingkat kekerabatan yang lebih dekat jika dibandingkan dengan bahasa Sasak-Sumbawa maupun bahasa Sasak-Bima.

5. Bahasa Sasak, bahasa Sumbawa, dan bahasa Bima termasuk dalam kategori keluarga (family) bahasa. 


\section{Daftar Pustaka}

Akbar, Osra M, dkk. 1985. Kamus Sumbawa-Indonesia. Jakarta: Pusat Pembinaan dan Pengembangan Bahasa Departemen Pendidikan dan Kebudayaan.

Bakar, Aboe, dkk. 1985. Kamus Sasak-Indonesia. Jakarta: Pusat Pembinaan dan Pengembangan Bahasa Departemen Pendidikan dan Kebudayaan.

Keraf, Gorys. 1996. Linguistik Bandingan Historis. Jakarta: Gramedia Pustaka Utama.

Kesuma, Tri Mastoyo Jati. 2007. Pengantar (Metode) Penelitian Bahasa. Yogyakarta: Carasvatibooks.

Mahsun. 2005. Metode Penelitian Bahasa: Tahapan Strategi, Metode dan Tekniknya. Jakarta: PT Raja Grafindo Persada.

Melalatoa, M.J, dkk. 1985. Kamus Bima-Indonesia. Jakarta: Pusat Pembinaan dan Pengembangan Bahasa Departemen Pendidikan dan Kebudayaan.

Parera, Jos Daniel. 1991. Kajian Linguistik Umum Historis Komparatif dan Tipologi Struktural Edisi Kedua. Jakarta: Erlangga.

Pateda, Mansyur. 1988. Linguistik (Sebuah Pengantar). Bandung: Angkasa.

Robbins, R. H. 1992. Linguistik Umum (Sebuah Pengantar). Yogyakarta: Kanisius.

Saidi, Shaleh. 1994. Linguistik Bandingan Nusantara. Flores-NTT: Nusa Indah.

Sudarno, M. Ed. 1994. Perbandingan Bahasa Nusantara. Jakarta: Arikha Medika Cipta. Sudaryanto. 1988. Metode Linguistik: Bagian Kedua Metode dan Aneka Teknik.

Pengumpulan Data. Yogyakarta: Gadjah Mada University Press. 1993. Metode dan Aneka Teknik Bahasa. Seri ILDEP. Yogyakarta:

Duta Wacana Universitas Press.

Wurm, S.,A., \& B. Wilson. 1978. English finderlist of Reconstructions In Austronesian Languages (Post-Brandstetter). Australia: Department of Linguistics Research School of Pasific Studies.

\section{Sumber dari internet}

http://www.linguistikid.com/2016/11/kajian-dan-jenis-tipologi-bahasa.html 